\title{
ICTs for education and development in rural communities \\ Project proposal
}

\author{
Sithabile Magwizi \\ Global Teenager Project Coordinator / Facilitator, World Vision International Zimbabwe, 59 \\ Joseph Road, Mount Pleasant, Harare, Zimbabwe. Tel : +263 4301715 / 301709 / 301172; \\ Fax : +2634301330, Mobile : +26391331369
}

stabile_urenje@wvi.org

Abstract: Proficiency in ICT skills is now regarded as important as basic reading and writing skills. In order to achieve computer literacy among the entire population, ICTs should be incorporated into the formal education system of a country. It must be noted however, that this process does not begin and end with putting computers in schools. Maximum use and benefits can only be derived through corresponding changes in approach to teacher training, curriculum development and administration. Overall, the support from teachers and the community is necessary to ensure the success of strategic initiatives. This can only be achieved by involving input from representatives of all stakeholder groups, for the development and implementation of the necessary policies and strategies. To gauge the extent to which this goal achieves transformational development, which is sustainable, practical measures will have to be put in place.

Key words: curriculum development, rural areas, teacher training 


\section{KEY ISSUES}

For development and implementation of the necessary policies and strategies for ICT development in education, the key stakeholders in the sector include:

- Students;

- Teachers;

- Parents;

- Education Institutions

- Early childhood;

- Elementary and secondary school;

- Postsecondary;

- Special education (For people with disabilities);

- Libraries and resource centers;

- Policy planners and administrators;

- Student loan and financial aid administrators;

- Career guidance and training providers;

- Employers;

- Authors, publishers and local book stores;

- Designers and suppliers of educational software;

- Vendors and service providers.

The following questions should be used as a guideline for identifying the key issues that need to be addressed in relation to the development of ICT in education:

- In what ways can ICT be used to enhance education delivery and learning in the classroom?

- How will teachers be trained, and how should they be motivated to use the technology?

- How can ICTs be employed to alleviate the high student to teacher ratio, and to extend the reach and capacity of the education system?

- What method should be employed to obtain the most equitable distribution of the limited ICT resources among the various rural schools?

- How to strike a balance between investing in ICTs in schools and spending on more immediate and basic educational needs (Can we justify the return on investment)?

- What methods can be employed to obtain and maintain the supporting physical and technical infrastructure required for ICT implementation?

- What steps should be taken to ensure a closer alignment between ICT education and the world of work? 
- In cases where investments have already been made in ICTs in schools why is the resource still being utilized?

\section{STRATEGIC OPPORTUNITIES}

"ICT has huge potential to engage pupils in ways that will help to realize their individual potential, whilst also offering teachers new opportunities to develop their professional skills in the classroom" - Estelle Morris

The concept looks at combining access to the Internet and networked computers to produce an innovative breakthrough child focused solution that is geared at achieving sustainable transformational development in the communities we work with. Effective use of ICT can enrich and enhance all aspects of schooling; teaching and learning, management and administration, and pupil's achievement.

\section{Improve educational delivery and learning}

- Computers can be used in classrooms to enhance learning by improving the quality of education in the classroom. Computer aided instructions gives opportunity for fast learners to flourish and slow learners to catch up through facilitation of self-paced learning. The Internet can be used in the classroom as a research tool to broaden horizons of both teachers and students.

- Equip school leavers with the ICT, information and learning skills needed for employability and lifelong learning and enable them to engage in a technological society.

- Support innovations in schools improving the effectiveness of schools and teachers.

\section{Facilitate distance education}

Distance education can be used to strengthen educational capacity and also to provide equitable access to limited resources especially in remote areas. Thus ICTs can be used to introduce or enhance distance education, by facilitating online courses and e-learning for both teacher and student. 
Distance education can provide a very useful supplement for the shortfalls in higher education and professional training institutions.

\section{Strengthen administration and decision making capacity}

ICT can be used for effective monitoring and management of the education system. (e.g. tracking and analysis of student performance, student record keeping, tracking of fee payment, etc.)

\section{Establishment of community resource center}

Computers in schools are usually used during school hours. There is possibility of extending computer use to provide:

1. Adult education and computer literacy classes on evenings, weekends, and during school vacation.

2. Other professionals (e.g. business people, medical personnel, etc.) in the community, e-mail and Internet services to communicate with family and friends all around the country or world.

3. Typing, faxing and printing services. This would benefit individuals in the community as a whole, and would reap a quick return on investment by charging a nominal fee.

\section{Extension of research facilities}

Creates the opportunity to link schools, libraries, resource centers and research facilities locally and internationally.

\section{CHALLENGES AND THREATS}

Effective implementation of policies and ideas necessitates identifying and forecasting potential challenges:

- Lack of ICT Expertise among policy makers;

- High opportunity cost of technology;

- Limited budget allocation for maintenance;

- Shortage of teachers with ICT skills;

- Possibility of widening achievement gap between schools. 


\section{CRITICAL SUCCESS FACTORS}

- Collaboration between major stakeholder groups is necessary to ensure successful implementation of these strategies.

- Physical infrastructure must be upgraded in schools in preparation for ICT introduction.

- Basic literacy is the foundation to computer literacy, so emphasis should not be shifted from basic literacy in favor of computer literacy.

- Regional and international collaboration is important to help learn from the success and mistakes of other countries.

- Curricula and teaching methods must be modified to incorporate the use of technology.

- Teacher involvement in planning and change is crucial for ensuring acceptance and support.

\section{FRAMEWORK FOR IMPLEMENTATION}

Unless ICT development is incorporated into the development plans of the school they risk misplaced investment and wasted opportunities for learners. Unless we are clear about what we want to achieve we will not be able to plan or achieve:

- Framework for implementation;

- Budget must be available and approved;

- Physical infrastructure upgraded in terms of power,space and security;

- Site inspection and collaboration with the school and teachers nominated to run the project;

- Network, hardware, software installations and Internet connection;

- Training;

- Commission;

- Networking (Try to find partners who are willing to add value to the project).

\section{IMPACT OF TECHNOLOGY ON SOCIETY}

Human societies, behaviours, systems of knowledge, and technologies are all interwoven in continual change. To describe the impact of some particular technology on society is a reductionist approach that risk missing the impact of society on the technology. Even when technologies that have been developed in centres of industry are exported to centres of continuity without 
any adaptive change to their design, they might be used in ways their designers had never imagined. (This is parodied in the opening scenes of the South African movie, The Gods Must Be Crazy. A soft drink bottle tossed from an airplane comes to serve an unmanageable variety of competing uses for the nomadic community that lives where it happens to fall.) These impact areas could be:

- Physical;

- Psycho-intellectual;

- Professional (skills for work);

- Economic;

- Cultural;

- Social;

- Environmental (e.g. changes in the use of physical space);

- Political. 